\title{
TESTE SENSORIAL DE UM PRODUTO ALIMENTAR INOVADOR: A NEOFOBIA ALIMENTAR COMO POSSÍVEL BARREIRA NO SETOR DE ALIMENTOS
}

G. da S. Goulartl ${ }^{1}$, T. Lucchese-Cheung ${ }^{2}$ e D. de O. Lima-Filho ${ }^{3}$
${ }_{1,2,3}$ Universidade Federal de Mato Grosso do Sul
gislaynegoulartgsg@gmail.com ${ }^{1}$
Submetido $24 / 03 / 2015$ - Aceito $18 / 03 / 2017$
DOI: $10.15628 /$ holos. $^{2017.2905}$

\section{RESUMO}

Este artigo apresenta os resultados de um estudo exploratório que pretendeu identificar as atitudes de homens e mulheres, residentes em Campo Grande/MS, em relação a um produto alimentar não familiar/inovador [o pão de queijo com cenoura], que foi desenvolvido pelo SENAI/MS. Desta forma optou-se pela realização de um grupo focal com a pretensão de realizar um teste sensorial. Para o tratamento dos dados foi realizada a análise de conteúdo. Os resultados dessa análise permitiram identificar que existe uma maior tendência de rejeição do produto alimentar inovador/não familiar pelos indivíduos do gênero masculino. A substituição de $60 \%$ do teor original de queijo por polpa de cenoura no preparo do pão de queijo foi melhor aceita pelos indivíduos do gênero feminino, mais preocupados com a saúde ou com a saúde da família. Além disso, deve-se atentar para o produto ter sido mencionado pelos consumidores como produto de diferenciação social.

PALAVRAS-CHAVE: Comportamento do consumidor, atitude, inovação alimentar, grupo focal.

\section{SENSORY TESTING A PRODUCT INNOVATIVE FOOD: FOOD NEOPHOBIA AS POSSIBLE BARRIER IN FOOD SECTOR}

\begin{abstract}
This article presents the results of an exploratory study which identified the attitudes of men and women living in Campo Grande/MS in relation to an unfamiliar food product/innovative [cheese bread with carrot], which was developed by SENAI/MS. This manner we chose to perform a focus group with the intention to perform a sensory test. For the treatment of data was performed content analysis. The results of this analysis have
\end{abstract}

identified that there is a greater tendency to rejection of innovative food product/unfamiliar by male individuals. Female individuals, more concerned with health or the health of the family, better accepted the replacement of $60 \%$ of the original cheese content for carrot pulp in the preparation of cheese bread. In addition, must pay attention as it the product has been mentioned by consumers as a product of social differentiation.

KEYWORDS: Consumer behavior, attitude, food innovation, focus group. 


\section{INTRODUÇÃO}

A taxa de inovação na indústria de alimentos brasileira está aumentando gradativamente conforme os dados da Pesquisa de Inovação PINTEC/2011. Entre 2009 e 2011, a taxa de inovação na indústria de alimentos foi de 40,9\%. Apresentando dispêndios realizados com atividades inovativas de $R \$ 7,8$ bilhões, com incidência de $2,02 \%$ na receita líquida de vendas. $E$ dispêndios realizados com pesquisa e desenvolvimento foram em torno de $\mathrm{R} \$ \mathbf{4 7 9}$ milhões, o que representa $0,12 \%$ de incidência na receita líquida de vendas. No mesmo período, a indústria de produtos alimentícios apresentou um total de 2.687 inovações em produtos, desse valor 2.288 são produtos novos apenas para a empresa e 483 são produtos novos para o país (IBGE, 2013). Esse aumento no investimento em inovação pela indústria de alimentos pode ser confirmado quando observado os dados levantados pela ABIA [Associação Brasileira das Indústrias de Alimentação] que relevam que em 2013 foram investidos no setor $R \$ 11,5$ bilhões em atividades inovativas, e destes R\$ 920 milhões foram destinados para pesquisa e desenvolvimento (Abras, 2014).

Entretanto, o EUFIC (2014) ressalta que a maioria dos novos produtos lançados no mercado não obtém sucesso e sua produção é descontinuada. O sucesso das inovações depende da aceitabilidade do consumidor, apensar das tendências de consumo de novos produtos alimentares e/ou com inovações existem barreiras que podem influenciar de forma negativa a aceitação desses produtos, por exemplo, a neofobia alimentar. Autores (Camarena, Sanjuán, \& Philippidis, 2011; Sanjuán-López, Philippidis, \& Resano-Ezcaray, 2011; D'Antuono \& Bignami, 2012; Fernández-Ruiz, Claret, \& Chaya, 2013), em publicações mais recentes, reiteram as afirmações sobre a definição de neofobia corroborando com as mais antigas de que a neofobia alimentar pode ser considerada como o medo ou receio do novo, do não familiar, podendo variar de cultura para cultura e apresentar diferentes níveis (Fischler, 1990; Pliner \& Hobden, 1992).

Uma das formas de se pesquisar as intenções de um indivíduo aceitar um determinado produto não familiar/inovador é por meio do estudo das atitudes dos consumidores de alimentos. O estudo das atitudes contribui para o conhecimento dos gostos, preferências e rejeições que o consumidor apresenta em relação a um determinado tipo de produto em especifico. Conforme Thiel e Demontrond (1997) conhecer as atitudes dos consumidores pode auxiliar na explicação da aceitação ou rejeição dos alimentos. Essa identificação pode contribuir, por exemplo, para segmentar mercados, escolher segmentos-alvo e criar e/ou avaliar estratégias de marketing (Blackweel, Miniard, \& Engel, 2005; Solomon, 2006).

A maneira como cada consumidor percebe determinado alimento dependerá de fatores relacionados à sua crença, em uma visão mais ampla, das suas experiências pessoais, familiares, sociais e culturais (Thiel \& Demontrond, 1997). Interessou-se no presente estudo identificar as atitudes de homens e mulheres, residentes em Campo Grande/MS, em relação a um produto alimentar não familiar/inovador [o pão de queijo com cenoura], que foi desenvolvido pelo SENAI/MS. Desta forma optou-se pela realização de um grupo focal com a pretensão de realizar um teste sensorial.

\section{FUNDAMENTAÇÃO TEÓRICA}

Cabe explicitar, inicialmente, que o conceito de 'atitude' é amplo e que ainda na atualidade há controvérsias, pois existem inúmeras e diferentes definições, modos de abordar e analisar a temática em discussões teóricas de diferentes áreas (Fishbein \& Ajzen, 1975; Ajzen, 2001). Simonson, Carmon, Dhar, Drolet e Nowlis (2001) em seu estudo "Consumer Research: In 
Searchof Identity" [Pesquisa do Consumidor: Em Busca da Identidade] fizeram uma revisão das principais tendências e dos 'campos' da pesquisa do consumidor publicados entre 1969 - 1999 nos principais periódicos da área de psicologia do consumo e de marketing, identificaram que muitos estudos tiveram o foco na atitude do consumidor pelo fato de ela influenciar no seu comportamento. Os autores relatam também que as teorias referentes à atitude advêm de contribuições da Psicologia Social.

Um dos conceitos de atitude mais citados na área marketing, tanto pelos livros-texto quanto pelos pesquisadores em geral que estudam as atitudes, é o de Fishbein e Ajzen (1975). Os autores afirmam que as atitudes são formadas a partir das crenças, pois uma vez que o indivíduo forma uma crença sobre determinado objeto, ele involuntariamente e concomitantemente adquire uma atitude para com o objeto, sendo essa atitude as suas avaliações sobre atributos ligados a ele por meio crença. Os autores explicam que a atitude pode ser constituída por três componentes: a cognição - que se refere à crença, conhecimento e/ou pensamentos referente ao objeto; o afeto - diz respeito aos sentimentos do indivíduo para com o objeto; e a conação tendências comportamentais do indivíduo em relação ao objeto.

Em relação aos alimentos, conforme Thiel e Demontrond (1997) conhecer as atitudes dos consumidores pode auxiliar na explicação da aceitação ou rejeição dos alimentos. Como cada consumidor percebe determinado alimento dependerá de fatores relacionados à sua crença, em uma visão mais ampla, das suas experiências pessoais, familiares, sociais e culturais. As crenças e as atitudes dos consumidores possuem considerável influência na compra e no consumo de alimentos, sobretudo quando o produto representa uma alternativa para o consumidor em relação aos alimentos familiares. Assim, quando se trata de alimentos não familiares o estudo das atitudes dos consumidores pode contribuir na segmentação de mercado, auxiliando a indústria, por exemplo, a elaborar estratégias que tendem a aumentar a aceitação desses produtos (Barrios \& Costell, 2004; Chen, 2007; Costell, Tárrega, \& Bayarri, 2010).

Costell et al. (2010) explicam que a atitude contribui para o entendimento da resposta que o consumidor apresenta em relação a determinado alimento. De modo simplificado, essa resposta é definida principalmente por quatro componentes: componente sensorial; componente afetivo; componente cognitivo; e componente comportamental [Quadro 1]. Podese observar que quando o objeto de atitude é um 'alimento' é acrescido o componente sensorial.

Quadro 1: Componentes de atitude quando o objeto é um 'alimento'

\begin{tabular}{|c|c|}
\hline Componente sensorial & Relacionado com as propriedades sensoriais do produto. \\
\hline Componente afetivo & $\begin{array}{c}\text { Responsável pela resposta positiva ou negativa em relação ao } \\
\text { produto alimentar. }\end{array}$ \\
\hline Componente cognitivo & Originário do conhecimento e opiniões sobre um produto alimentar. \\
\hline Componente comportamental & $\begin{array}{c}\text { Envolvimento ou intenções de ações que poderá refletir em um } \\
\text { comportamento futuro. }\end{array}$ \\
\hline
\end{tabular}

Fonte: Elaborado pelos autores com base em Costell et al. (2010)

Segundo os autores Costell et al. (2010) o componente sensorial deve ser considerado principalmente quando se trata da investigação de aceitação de alimentos, pois os consumidores geralmente buscam alimentos com determinadas características sensoriais. E complementam que a aceitação de um determinado alimento dependerá da resposta que ele conseguir dar às necessidades do indivíduo.

O presente estudo dará uma maior atenção ao componente afetivo de atitude, pelo fato de a pesquisa ter como objeto de estudo ser um produto alimentar inovador [o pão de queijo com cenoura]. Na maioria dos casos, o novo, o desconhecido e/ou o não familiar estão mais relacionado, em um primeiro momento, com as emoções e sentimentos dos indivíduos do que com os fatores cognitivos. Conforme Jiang, King e Prinyawiwatkul (2014), o comportamento 
alimentar dos indivíduos é influenciado pelas emoções, incluindo desde a escolha do alimento até a motivação e quantidade de alimento que será ingerido. A emoção é uma temática complexa que já foi abordado em inúmeros estudos, principalmente na área da psicologia, entretanto, devido a sua complexidade, é difícil encontrar na literatura uma definição única (Jiang et al., 2014). Para Sheth, Mittal e Newman (2001, p. 338) de modo geral "as emoções são a consciência da ocorrência de alguma excitação fisiológica seguida por uma resposta comportamental, juntamente com a avaliação do significado de ambas."

Segundo Bagozzi, Gopinath e Nyer (1999) a emoção consiste em um estado mental de prontidão que surge de avaliações situacionais ou do pensamento que não é planejado. $O$ que formam as emoções são, portanto, avaliações psíquicas únicas do indivíduo que avalia determinado objeto, de modo que cada indivíduo poderá ter uma reação diferente ou nula, quando exposto a um mesmo objeto. E em especial para a área de marketing, a emoção pode ser considerada como resposta afetiva distinta causada por uma experiência com um objeto de consumo.

Espinoza e Nique (2003) afirmam que as emoções não advêm somente da vontade do indivíduo em sentir ou não algo em relação a um objeto. Consideram que, de modo geral, as emoções espontaneamente acontecem e aparentam circundar o sistema racional e o livrearbítrio, embora as expressões possam ser controladas. Os autores (Espinoza \& Nique, 2003, p.3) explicam que as emoções, de forma simplificada, podem ser divididas em dois grupos: "Emoções Positivas - aquelas que envolvem atração, aproximação ou comportamento positivo; e Emoções Negativas - aquelas que envolvem fuga, recuo ou comportamento negativo."

Como pode ser observado, as influências dos hábitos alimentares, crenças, atitudes e opiniões sobre a escolha dos alimentos são importantes para compreender a aceitação ou rejeição de alimentos não familiares (Costell et al., 2010). Compreende-se que há indícios de novas tendências no comportamento do consumidor, entretanto, existem possíveis barreiras que podem impedir a aceitação de inovações no que tange aos alimentos, por exemplo, tendências de atitudes neofóbicas.

Quando se trata do consumo de um produto alimentar não familiar, Ritchey, Frank, Hursti e Tuorila. (2003) constataram que alguns indivíduos apresentam prazer em consumi-los e outros apresentam uma forte relutância. Conforme já mencionado, esse segundo comportamento, denominado neofobia alimentar, atua no subconsciente como uma função protetora em um ambiente de possíveis produtos nocivos ao organismo humano (Pliner \& Hobden, 1992; Yamamoto \& Lopes, 2004).

Segundo Visalberghi e Fragaszy (1995), a neofobia possui graus de rejeição que podem variar desde a completa rejeição em comer um novo alimento ou até a concordância em somente ingerir pequenas porções do mesmo. A maior parte dos estudos encontrados na literatura se interessara em investigar os fatores que possivelmente podem influenciar mais ou menos a ocorrência de neofobia em seres humanos. Tais investigações, em geral, preocuparamse mais em saber a diferença de comportamento em relação ao alimento novo quanto ao gênero, à idade, à renda, à escolaridade, aos ambientes participados, à cultura e aos aspectos sensoriais do produto (Pliner \& Hobden, 1992; Frank \& Klaauw, 1994; Koivisto \& Sjöden, 1996; Hursti \& Sjödén, 1997; Mooney \& Walborurn, 2001; Tuorila et al., 2001; Bäckström, Pirttilä-Backman, \& Tuorila, 2003; Nordin, Broman, Garvill, \& Nyroos, 2004; Schickenberg, Assema, Brug, \& Vries, 2006; Yamamoto \& Lopes, 2006; Meiselman, King, \& Gillette, 2010; Camarena et al., 2011; Sanjuán-López et al., 2011; D'Antuono \& Bignami, 2012; Fernández-Ruiz et al., 2013).

Contudo, este trabalho tem como foco o fator gênero, constatou-se que os estudos a respeito das diferenças de gêneros quanto à neofobia alimentar apresentam resultados 
controversos. Alguns estudos sugerem que as mulheres tendem a serem mais neofóbicas, outros apontam os homens e há os que não encontraram diferenças significativas entre gêneros, como podem ser observados no Quadro 2.

Quadro 2: Influência da variável gênero no nível de receio e/ou medo em adultos

\begin{tabular}{|l|c|c|}
\hline \multicolumn{1}{|c|}{ Autores } & Amostra & Gênero \\
\hline Pliner e Hobden (1992) & 41,35 e 80 & $\mathrm{~ns}$ \\
\hline Frank e Klaauw (1994) & 719 & $\mathrm{f}+$ \\
\hline Koivisto e Sjöden (1996) & $231^{\mathrm{a} / \mathrm{c}}$ & $\mathrm{m}+$ \\
\hline Hursti e Sjödén (1997) & $722^{\mathrm{c}^{*}}$ & $\mathrm{~m}+$ \\
\hline Mooney e Walborurn (2001) & 113 & $\mathrm{f}+$ \\
\hline Tuorila et al. (2001) & 1083 & $\mathrm{~m}+$ \\
\hline Bäckström et al. (2003) & $44^{\mathrm{g}}$ & $\mathrm{m}+$ \\
\hline Nordin et al. (2004) & 200 & $\mathrm{f}+$ \\
\hline Yamamoto e Lopes (2006) & 406 & $\mathrm{f}+$ \\
\hline Meiselman et al. (2010) & 1567 e 6843 & $\mathrm{ns*}$ \\
\hline Camarena et al. (2011) & 270 & $\mathrm{~m}+$ \\
\hline Sanjuán-López et al. (2011) & 208 & $\mathrm{f}+$ \\
\hline D' Antuono e Bignami (2012) & 283 & $\mathrm{~ns}$ \\
\hline Fernández-Ruiz et al. (2013) & 309 & $\mathrm{~ns}$ \\
\hline
\end{tabular}

$\mathrm{a} / \mathrm{c}=$ adultos e crianças; $\mathrm{c}^{*}=$ crianças de 7 a 17 anos (+ familiares não contabilizados, para o presente estudo será retratado somente o comportamento dos pais); $\mathrm{g}=$ grupo focal $(\mathrm{n}=9)$; $\mathrm{ns}=$ não significante; ${ }^{* *}=$ Pouco ou nenhum efeito do gênero sobre a neofobia; $f=$ feminino; $m=$ masculino; $(+)=$ mais neofobia; $(-)=$ menos neofobia.

Fonte: Elaborado pelos autores

Os dados apresentados no Quadro 2 serão utilizados por este artigo no tópico de resultados e discussões. Pretende-se utilizar os resultados dessas pesquisas para melhor compreender possíveis tendências de intenções de comportamentos neofóbicos em relação ao gênero, o medo e/ou receio em adultos, declarados pelos consumidores no estudo empírico.

\section{PROCEDIMENTOS METODOLÓGICOS}

O presente estudo faz parte de uma pesquisa mais ampla financiada pelo CNPq que está sendo desenvolvida pela Universidade Federal de Mato Grosso do Sul [UFMS] em parceria com Serviço Nacional de Aprendizagem Industrial de Mato Grosso do Sul [SENAI/MS], que tem como objetivo definir uma identidade de marca para um produto alimentar inovador.

O objeto de estudo é um pão de queijo com cenoura desenvolvido pelo SENAI de Dourados/MS. Para o preparo do produto foram utilizados os mesmos ingredientes do pão de queijo tradicional, o diferencial foi a substituição de $60 \%$ do teor original de queijo por polpa de cenoura. Essa substituição gerou uma redução de $40 \%$ das gorduras totais e proporcionou mais vitaminas e fibras ao produto. Este produto alimentar representou Mato Grosso do Sul na categoria produto inovador da etapa nacional do Inova Senai realizado no Anhembi, em São Paulo (SP) em 2012, durante a Olimpíada do Conhecimento. 
Para o estudo utilizou-se o instrumento qualitativo, denominado grupo focal que é um método de coletar dados de forma dinâmica e direta por meio do discurso de um grupo (Vieira \& Tibola, 2005). Esse tipo de coleta de dados é indicado para esse estudo, pois segundo Barrios e Costell (2004) é uma técnica que permite identificar as atitudes dos indivíduos não somente por intermédio da fala, mas também por meio de suas expressões corporais e emoções. E conforme Sá (1998, p. 93) os grupos focais "de certo modo simulam as conversações espontâneas pelas quais as representações são veiculadas na vida cotidiana" e eles podem "fazer emergir uma boa quantidade dos mesmos temas e argumentos que fariam parte de uma conversação sobre o assunto no ambiente natural".

Para que fosse possível conhecer melhor as atitudes de homens e mulheres diante de um produto alimentar não familiar, foram selecionados 5 homens e 5 mulheres com o mesmo nível de escolaridade [nível superior completo] e faixa etária [de 30 a 50 anos], para não enviesar os resultados. Entretanto compareceram para a realização do grupo no dia 11 de junho de 2013, no período matutino [ $\pm 10 \mathrm{~h} 00 \mathrm{~min}$ ] no prédio do SENAI/MS em Campo Grande/MS, 4 homens e 5 mulheres. Assim, o grupo foi formado por 9 participantes, o que não compromete os resultados do estudo, pois segundo Vergara (2005) havendo homogeneidade no grupo, uma composição ideal de grupo focal é formada entre 6 e 12 participantes.

O tema do grupo foi o produto alimentar inovador que será lançado em breve no mercado, assim, de modo geral, o debate recaiu sobre um produto familiar [pão de queijo/ pão de queijo congelado], e posteriormente, foi apresentado o produto inovador [pão de queijo com cenoura]. Para a condução do grupo contou-se com o auxílio de 1 moderadora (VIEIRA; TIBOLA, 2005). O debate do grupo foi dividido em 2 partes:

- Na primeira parte, a moderadora motivou os participantes a relatarem suas atitudes, sentimentos e opiniões apresentando-lhes imagens de pão de queijo, abordando desse modo o produto familiar. Foram abordados aspectos do consumo como momento e lugar do consumo, percepções de qualidade, benefícios procurados no produto, e finalizou-se buscando conhecer se há algum receio no consumo de uma marca nova; e

- Na segunda parte, foi realizada a apresentação do produto inovador/não familiar [pão de queijo com cenoura]; nesse momento, os participantes foram convidados a realizar um teste sensorial do pão de queijo com cenoura [o produto alimentar foi servido ainda quente e os participantes poderiam degustar a vontade]. Em seguida os mesmos foram estimulados a relatar suas opiniões, sentimentos e emoções em relação ao produto. A moderadora procurou, no decorrer do grupo focal, realizar perguntas e nortear a discussão de modo a identificar aspectos de possíveis tendências de neofobia alimentar na fala e nas atitudes dos participantes.

Para a análise dos dados foi realizada a análise de conteúdo que segundo Bardin (2007, p. 42) é

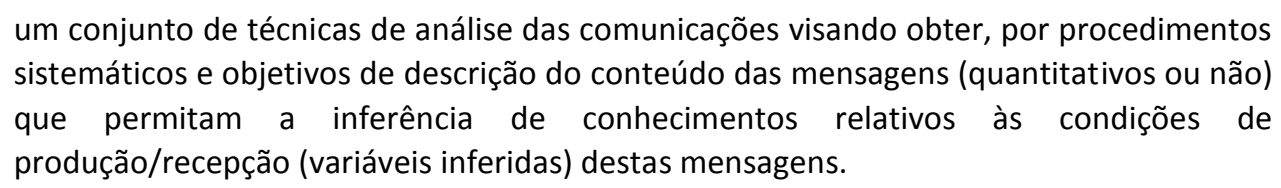

Foi escolhida essa análise em detrimento de outras, pelo fato de ela permitir analisar não somente o discurso verbal dos consumidores, mas também a linguagem não verbal (Bardin, 2007). Por exemplo, tratando-se de neofobia alimentar as pessoas tendem a declarar que não são neofóbicas, que gostam de inovações alimentares, mas à medida que elas são questionadas de modo indireto revelam suas verdadeiras atitudes. Isso também pode ser verificado com as expressões corporais dos mesmos, pois às vezes relatam algo sobre um determinado produto, 
mas suas expressões corporais revelam o oposto da fala. Assim, a análise de conteúdo foi realizada com base nas transcrições das falas dos participantes e gravação audiovisual do grupo para que fosse possível recuperar com melhor riqueza de detalhes as atitudes dos mesmos. Cabe salientar, que um termo de consentimento livre esclarecido foi apresentado aos participantes do grupo que concordarem com todos os elementos fundamentais contidos no termo, sendo que todos os participantes autorizaram a gravação, bem como permitiram que trabalhos científicos expusessem suas declarações.

Destaca-se que as falas serão apresentadas exatamente como foram declaradas. E que o nome dos participantes foram omitidos nas transcrições das declarações para que fossem mantidas em sigilo suas identidades. Desse modo, quando necessário, os participantes serão identificados pela letra $\mathrm{P}$ associada aos números de um a nove [quantidade de indivíduos que compuseram o grupo focal] e ao seu gênero [H-homem; $\mathrm{M}$ - mulher].

\section{RESULTADOS E DISCUSSÕES}

Como este trabalho considera que os comportamentos alimentares dos comensais são, também, determinados por fatores culturais [normas, regras, valores e tabus alimentares transmitidos através dos ambientes e grupos sociais], julgou-se conveniente apresentar as opiniões declaradas pelos participantes do grupo focal através dos trechos da fala dos mesmos. Considera-se que a análise do conteúdo das falas é apropriada quando se pretende compreender a ação das normas sociais sobre os comportamentos dos sujeitos (Jodelet, 2001).

Para que os participantes tivessem as sensações, impressões, lembranças e sentimentos aguçadas, foram apresentadas imagens do produto familiar [pão de queijo] e questionado se pão de queijo é comida e se todas as pessoas podem consumir. Os integrantes do grupo acreditam que o pão de queijo é uma comida e que todos podem consumi-lo, exceto bebês e indivíduos que tenham alguma restrição alimentar.

\footnotetext{
"Sim! É comida, porque nem tudo que se come é comida. [...] Não é [comida] de bebê, por exemplo. [...] E bebê não tem dente." (P4-M)

[para bebê não pode], "em virtude de alguns ingredientes, porque tem muito queijo, óleo e polvilho." (P2-M)

"Depende se a pessoa tiver alguma restrição alimentar, ela já não pode comer." (P8-M)

"Principalmente devido à lactose." (P7-H)

“Eu conheço uma pessoa que não pode comer nenhum tipo de derivado do leite. Ela gosta muito do cheiro do pão de queijo, mas teve que parar de comer." (P3-H)
}

Foi questionado, então, se o consumo de pão de queijo é igual para ambos os gêneros. Constatou-se que $77,78 \%$ dos participantes consideram que as mulheres consomem mais quando comparadas com os homens. Os mesmo apresentam como possíveis justificativas o fato de que os indivíduos do gênero masculino preferem algo que dê mais saciedade, que seja maior, que mate a fome, por exemplo, um sanduíche. Essa justificativa é válida à medida que todos os participantes do gênero masculino declararam que preferem um sanduíche em detrimento de um pão de queijo e que, de modo geral, são as mulheres que os influenciam a consumir pão de queijo. Por meio das declarações de intenções de comportamento de consumo dos participantes em relação ao produto alimentar familiar foi possível constatar que os indivíduos do gênero masculino tendem a preferir alimentos que deem mais saciedade que um pão de queijo, Macaux 
(2001), Robinson e Thomas (2004) e Cooke e Wardle (2005) explicam que, geralmente, indivíduos do gênero masculino escolhem mais alimentos gordurosos e açucarados, carne e ovos do que o gênero oposto.

\begin{abstract}
"Eu tenho a impressão que é a mulher que come mais. [...] Eu pelo menos aprendi a gostar de pão de queijo por causa de uma mulher. Pura influência." [risos] (P1-H)

"A mulher faz aquele lanchinho da tarde. Aí pensa no pão de queijo, já o homem vai querer uma coisa maior, mais consistente. [...]Eu acho que o sanduíche passa essa impressão de que vai saciar muito mais do que um pão de queijo" (P6-M) [todos os homens concordaram]

"Eu acho também que a mulher come mais. [...] Ao mesmo tempo eu acho que o habito alimentar do homem é mais simples. É claro que toda regra tem uma exceção. [...] Dependendo do homem, ele come um sanduíche e já está bom. Já a mulher entre um sanduíche e um pão de queijo, a mulher vai fazer a opção pelo pão de queijo. [...] Eu acho que o homem é mais simples nesse aspecto, ele é mais prático. A mulher já aprecia mais o produto [pão de queijo]." (P4-M)
\end{abstract}

"Aparentemente o pão de queijo tem menos calorias, por isso as mulheres preferem ele. [...] Eu não gosto de pão de queijo. Eu como às vezes, assim, por educação, ainda mais porque a minha mulher gosta de pão de queijo. [...] Como, principalmente, quando ela compra com goiabada, ai eu consumo mais é pelo doce mesmo." (P5-H)

"O homem já vai preferir o sanduíche do que o pão de queijo pela praticidade, porque geralmente quando ele come é porque quer matar a fome. [...] Se optar pelo pão de queijo ele vai ter que comer uns 15 pão de queijos para matar a fome." (P7-H)

"A minha mulher gosta muito de queijo, ai ela compra direto pão de queijo. [...] $\mathrm{O}$ pão de queijo você vai saborear. É como se fosse um aperitivo. [...] É como se fosse um foco 'comer e matar a fome'. [...] Olha... quando eu como pão de queijo é sem fome, só para matar a gula mesmo." (P3-H)

Em relação ao momento de consumo observou-se nas declarações uma maior tendência de consumo no lanche da tarde, entretanto o pão de queijo também é consumido em menor frequência no café da manhã e à noite. Os participantes revelam que, geralmente, quando o pão de queijo congelado é assado em casa é para receber visita.

“Na minha casa sempre tem pão de queijo [congelado]. Eu não costumo comer muito a tarde, mas é claro que nos finais de semana quando eu recebo alguém, eu asso. Porém, durante a semana eu asso ele a noite, porque eu não janto. E também eu não lancho a tarde, então eu chego em casa as sete da noite e eu faço para mim e para minha filha e para quem estiver ali." (P4-M)

“[...] Eu já vejo para a mulher como uma praticidade, comprar um pão de queijo e ter ele congelado no freezer... você retirar e fazer para uma visita ou alguma coisa para mim é algo muito prático. [...] É algo que todo mundo come." (P8-M) [4 participantes concordaram o a afirmação]

"Na minha casa é o seguinte quando vamos ao mercado, pelo menos a cada duas vezes por semana a gente vai ao mercado e minha esposa pega e compra o pão de queijo [congelado]. E aí ela faz de manhã e leva para comer no serviço a tarde. Então, eu pego só uns 3 ou 4 pão de queijos e ela pega o restante. [...] No final de semana, aí a gente tem uma maior preferência mesmo de fazer um cafezinho com pão de queijo para o café da manhã." (P3-H)

É possível recuperar na fala dos participantes que o pão de queijo congelado é sinônimo de praticidade, pois é uma comida prática de se fazer, exigindo pouca dedicação e tempo para o 
preparo. Isso corrobora com estudos que identificaram essas tendências, como: a busca por produtos alimentares práticos, a redução no tempo destinado ao preparo dos alimentos e o das mudanças dos hábitos com a inserção da mulher no mercado de trabalho (Garcia, 1994; Garcia, 2003; Poulain, 2004; El-Kareh, 2008; Federação..., 2010; Ventura, 2010; Abras, 2013).

\begin{abstract}
“Eu já vejo como [uma] praticidade no pão de queijo. Hoje você já não precisa mais necessariamente fazer em casa o pão de queijo, você já encontra ele pronto. Eu já vejo numa praticidade da mulher, assim, porque a mulher... hoje eu já vejo a mulher muito mais prática, ela não tem mais aquele tempo de estar ali fazendo a massa. Ela já busca algo que já esteja pronto. Aí é lógico que vai ter que passar por um padrão de qualidade, tem que ser um sabor bom, porque já aconteceu de eu comprar um pão de queijo [congelado] e chegar em casa e ele não ter um sabor muito bom." (P8-M) [3 participantes concordaram com essa declaração]
\end{abstract}

"Eu só faço em casa, porque já compro pronto" (P4-M)

O pão de queijo pode ser considerado como um produto alimentar que representa convivialidade, uma vez que os participantes apresentam relatos que demonstram que o consumo praticamente nunca é sozinho. Em relação aos benefícios que os consumidores pretendem encontrar quando compram um pão de queijo congelado estão relacionadas com a textura, sabor, leveza e que tenha uma aparência melhor do que os que estão disponíveis no mercado.

“[o pão de queijo] é uma questão de sabor, de convívio com as pessoas, já o sanduíche você come de uma vez e acabou, encerrou. $O$ pão de queijo não, você pode pegar mais um, conversa um pouco, aí o bate-papo se prolonga. [...] Um pão de queijo congelado que eu gosto, vou até te falar a marca chama ' $X$ ' sempre eu vejo lá no 'mercado $Z$ '. É um que eu acho que atende bem as expectativas... agora o que eu vejo de diferente no pão de queijo é a leveza. A leveza do pão de queijo de Minas, porque eu já morei em Minas, ele é muito simples, ele parece que só têm polvilho, um pouco de queijo e nada mais, levinho. Você come e ele quase que derrete na sua boca. E esse da marca ' $X$ ' ele atende um pouco as minhas expectativas... só que ele é um pouco maior, o de minas ele já é geralmente [menor] e não é muito grande, é uma questão que eles fazem... eh... eh... o convívio, é sentar à tarde, é feito o pão de queijo num formato pequeno para você comer vários e tenha aquela conversa, então lá não tem grande." (P2-M)

"Eu acho que essa parte não só da textura, mas também a parte da leveza que é para mim o que mais chama a atenção. [...] o que parece que dá a vontade de comer vários" (P3-H)

"[O do mercado] o gosto não é bom" (P1-H) [2 participantes concordam]

"Até agora não encontrei nenhum que me agradasse" (P6-M)

"O que acontece, eu acho que é algo emergencial comprar no mercado [o pão de queijo congelado], para você ofertar ali e improvisar é mais isso. Porém o pão de queijo que eles disseram o da 'cafeteria $W$ ', para mim é o melhor, mas tem outras cafeterias, confeitarias e padarias que também tem um bom. [...] O do mercado eu compro por emergência mesmo, entendeu? Porque tem toda a diferença não só na textura como também no sabor. Principalmente o sabor não é a mesma coisa do [pão de queijo] da 'cafeteria W' como o que eu compro lá no mercado" (P4-M)

"o pão de queijo congelado tem muita diferença daquele da padaria, falta sabor" (P6-M)

“[...] a aparência do congelado é muito diferente [...] não é airado, não explode e não fica uma casca $[\ldots]$ ".. (P7-H) 
Assim, observa-se que a tendência de procura pelo produto seria mais pelas mulheres. Em geral, os participantes não têm ainda uma marca específica que atenda suas expectativas nem apresentam tendências neofóbicas em relação a uma marca desconhecida, pois $8 / 9$ participantes não citaram nenhuma marca de pão de queijo congelado. Esse fato indica que uma boa estratégia para as empresas do setor fidelizarem novos consumidores poderia ser inovando em marketing, uma vez que foi identificado que as mulheres são consumidoras mais assíduas e são elas que influenciam o consumo dos demais, considerando, também os aspectos citados como convivialidade, praticidade, ser consumido no lanche e para receber visita. Ou inovar no produto - textura, sabor e aparência.

Na segunda parte do grupo quando foi apresentado o produto inovador, o pão de queijo com cenoura, constatou-se pelo silêncio e pela expressão facial dos indivíduos do gênero masculino que não gostaram muito da ideia. Já os indivíduos do gênero feminino se mostraram mais interessados em saber um pouco mais sobre o produto. Nessa etapa, a moderada do grupo explicou que o pão de queijo com cenoura é um produto inovador que foi desenvolvido em uma unidade do SENAI/MS no município de Dourados por técnicos e alunos do curso de panificação, sendo um dos destaques no evento nacional INOVA SENAI 2012, e que em breve estará no mercado. Após os participantes realizarem o teste sensorial foi explicado, ainda, que o que há de mais inovador nesse produto é a substituição de $60 \%$ do teor original de queijo por polpa de cenoura. Essa substituição gerou uma redução de $40 \%$ das gorduras totais e proporcionou mais vitaminas e fibras ao produto. A moderadora esclareceu que os participantes poderiam comer quantas unidades desejassem do produto e que em seguida relatassem suas opiniões, sentimentos e emoções em relação ao produto inovador, Tabela 1.

Tabela 1: Declarações do grupo focal em relação ao produto alimentar inovador

\begin{tabular}{|c|c|}
\hline Homens & Mulheres \\
\hline $\begin{array}{c}\text { "O gosto é diferente... não tem gosto de pão de } \\
\text { queijo" }\end{array}$ & $\begin{array}{l}\text { "Não tem gosto de pão de queijo e nem de } \\
\text { cenoura" }\end{array}$ \\
\hline $\begin{array}{c}\text { "Ele é mais adocicado, mas a textura do queijo } \\
\text { está presente. [...] Eu tenho a sensação de que } \\
\text { tem erva doce" }\end{array}$ & $\begin{array}{l}\text { “A textura do queijo está mesmo presente." } \\
\text { "Está bom, é leve" }\end{array}$ \\
\hline "Ele é mais puxento. Ele é mais borrachento" & "Ele é crocante também" \\
\hline $\begin{array}{l}\text { “Ele não é embatumado, mas também não é } \\
\text { assim tão levezinho. É mais aerado." } \\
\text { “Para mim ele tem certa casca e o miolo é } \\
\text { levezinho, mas um pouco condensado. Mas ele } \\
\text { não é como se fosse um bolo fofo." }\end{array}$ & $\begin{array}{l}\text { “A textura dele está boa, porém é claro que não } \\
\text { está igual ao pão de queijo de minas que é mais } \\
\text { leve. Ele está mais para condensado. É a minha } \\
\text { visão, por ele estar mais puxento considerando } \\
\text { que ele não tem só queijo, tem cenoura também. } \\
\text { Por isso é diferente. Né? }\end{array}$ \\
\hline $\begin{array}{c}\text { “[...] é mais consistente." } \\
\text { "Eu não consegui sentir nem o sabor da cenoura, } \\
\text { nem do queijo" }\end{array}$ & $\begin{array}{c}\text { "É diferente do tradicional, porém o valor } \\
\text { nutricional deve ser bem melhor, assim uma } \\
\text { pessoa que faz dieta ou tem alguma restrição é } \\
\text { claro que a pessoa optaria" }\end{array}$ \\
\hline $\begin{array}{l}\text { "Para o padrão sul-mato-grossense precisa ter um } \\
\text { pouco mais de sal" } \\
\text { "Talvez se ele fosse um pouco mais salgado seria } \\
\text { interessante" }\end{array}$ & $\begin{array}{c}\text { "Eu compraria sem problema nenhum um pão de } \\
\text { queijo com cenoura. Para mim é gostoso tão } \\
\text { quanto o outro, cada um no seu jeito, mas é } \\
\text { diferente" }\end{array}$ \\
\hline $\begin{array}{l}\text { “O primeiro toque na língua é doce" } \\
\text { "Comprar para experimentar é sempre } \\
\text { interessante" [todos os homens começaram a rir }\end{array}$ & $\begin{array}{l}\text { "demoraria um pouco para acostumar, mas é } \\
\text { bom" } \\
\text { "Parece mais com o feito em casa" [três }\end{array}$ \\
\hline
\end{tabular}




\begin{abstract}
com essa afirmação]
"A minha esposa não iria comer, não!"

"Eu não sei se pegaria no mercado... se tiver ali no mercado a pessoa prova um ou dois, mas ela volta para o tradicional. Por isso eu não sei se pegaria no mercado. [...] para uma empresa grande que lançasse atenderia uma parcela muito pequena de pessoas também"

"se o cara tivesse alguma restrição alimentar consumiria, sim."
\end{abstract}

"Eu não sei se trocaria o tradicional por ele" participantes concordaram com a afirmativa]

"Para mim não parece nem com o caseiro e nem com o de saquinho. Ele parece que é mais durinho até para mastigar, sabe?"

"Quando você mastiga ele solta, não é uma coisa embatumada"

"[...] quando você morde ele volta ao formato dele"

"Falta o sabor da cenoura"

“Para mim não tem que ter o sabor da cenoura, está bom"

"As pessoas daqui comem com mais sal, mas para mim está bom"

“Eu pelo menos compraria"

“Eu compraria, mas não como substituto do tradicional"

"É bom, mas não substituto"

“Na minha visão se for para causar e falasse assim: 'eu tenho um pão de queijo tradicional e um com cenoura'. Ai eu acho que causa mais o de cenoura, se for para querer impressionar. Porque querendo ou não é algo diferente e tudo que é diferente as pessoas tem curiosidade. Aí depois ela vai falar gostei ou não"

"Não sei se é um substituto"

"Discordo que seria uma parcela pequena de pessoas que consumiria. [...] Creio que precisa trabalhar com a mente das pessoas, porque as pessoas estão muito acostumadas com aquele tradicional. Teria que desfazer e trazer novos conceitos. A ideia seria essa, uma inserção mesmo talvez no mercado, acredito que talvez precisaria de uma propaganda mais agressiva"

"Vocês talvez deveriam ver as mulheres como público alvo. [...] para mim o público alvo seria as mulheres acima dos 30 anos, as mães. Por exemplo, a mãe que de vez em quando quer fazer uma dieta, a mãe que se preocupa com a filha é adolescente. Então o público alvo tem que ser esse aí 'a consciência', para que ela já esteja educando desde de pequeno os filhos."

"seria mais saudável"

Fonte: Dados da pesquisa (2013)

Em geral, o grupo concordou que o pão de queijo com cenoura é bom, mas é bem diferente do tradicional. Esse produto alimentar poderia ser para algumas ocasiões, por exemplo, para impressionar uma visita. Mas não serve como substituto do tradicional. Seria visto como uma variedade que tende a ser interessante para pessoas que estão de dieta, para pessoas preocupadas com a saúde, em outras palavras, esse produto alimentar se encaixaria no 
segmento do "faz bem", direcionado para indivíduos que buscam saudabilidade (Federação..., 2010; Nielson, 2013).

Foi possível perceber por meio da análise da fala dos participantes que as mulheres tiveram uma maior aceitação do produto alimentar inovador, demonstrando menos atitudes neofóbicas do que os homens. Um dos participantes do gênero masculino depois da experiência sensorial não quis comentar sobre o produto e os demais até comentaram sobre as características do pão de queijo com cenoura, mas quando a moderadora indagou se eles comprariam, eles disseram que 'sim', entretanto começaram a rir e apresentavam expressões irônicas. Neste contexto, o presente resultado corrobora com os estudos que apontam que os homens possuem maiores tendências neofóbicas do que as mulheres (Koivisto \& Sjöden, 1996; Hursti \& Sjödén, 1997; Tuorila et al.,2011; Bäckström et al., 2003; Camarena et al., 2011).

Um motivo provável para essa diferença de comportamento segundo Mooney e Walborum (2001), é que um dos principais fatores considerados para a rejeição de alimentos entre os homens são o sabor e os aspectos hedônicos, pois esses tendem a rejeitar mais vegetais do que as mulheres. Outros estudos também constataram que os indivíduos do gênero feminino tendem a consumir mais legumes que os do gênero masculino por influências socioculturais e biológicas (Macaux, 2001; Robinson \& Thomas, 2004; Cooke, \& Wardle, 2005).

Assim, de modo geral, em relação a análise de resultados, foi possível identificar fatores que determinaram as opiniões, motivações e atitudes da amostra em relação ao produto pão de queijo e o produto inovador. Como sugestão aos agentes do setor de alimentos e interessados em lançar novidades no mercado, julga-se conveniente observar quais foram as diferenças de comportamento encontradas entre os gêneros. Uma política de marketing mais eficiente poderia ser construída a partir das constatações deste trabalho científico.

\section{CONSIDERAÇÕES FINAIS}

Os resultados apresentados permitiram comprovar que a substituição de $60 \%$ do teor original de queijo por polpa de cenoura no preparo do pão de queijo foi melhor aceita pelos indivíduos do gênero feminino. Constatou-se que a não familiaridade em relação a um alimento pode provocar níveis distintos de neofobia alimentar. A análise de conteúdo possibilitou identificar que existe uma maior tendência de rejeição do produto alimentar inovador/não familiar pelos indivíduos do gênero masculino.

O teste sensorial em conjunto com a análise de conteúdo possibilitaram uma melhor identificação das atitudes dos consumidores em relação ao produto inovador, o pão de queijo com cenoura, pode-se perceber que ele é melhor aceito entre consumidores do gênero feminino, mais preocupados com a saúde ou com a saúde da família. Além disso, deve-se atentar para o produto ter sido mencionado como produto de diferenciação social, quando integrantes revelaram que poderiam causar boa impressão a uma visita. Tais informações são importantes, por exemplo, para a realização de uma campanha eficiente de comunicação do produto.

\section{REFERÊNCIAS}

Ajzen, I. (2001). Nature and operation of attitudes. Annu. Rev. Psychol, 52, 27-58.

Associação Brasileira de Supermercados - ABRAS. (2013). Aumentam as vendas de comida congelada. Recuperado de http://www.abras.com.br/clipping.php?area=16\&clipping=39939.

Associação Brasileira de Supermercados - ABRAS. (2014). Apesar de garantir bom resultado, investimento em inovação é pequeno. 2014. Recuperado de 
<http://www.abras.com.br/clipping.php?area=1\&clipping=47642>.

Bäckström, A., \& Pirttilä-Backman, A. M., Tuorila, H. (2003). Dimensions of novelty: A social representation approach to new foods. Appetite, 40, 299-307.

Bagozzi, R.P., Gopinath, M., \& Nyer, P.U. (1999). The Role of Emotions in Marketing. Journal of the Academy of Marketing Science, 27(2), 184-206.

Bardin, L. (2007). Análise de Conteúdo (4a ed.). Lisboa, Portugal: Edições 70.

Barrios, E. X., \& Costell, E. (2004). Review: Use of Methods of Research into Consumers' Opinions and Attitudes in Food Research Food. Sci Tech Int, 10 (6), 359-371.

Blackwell, R. D., Miniard, P. W., \& Engel, J. F. (2005). Comportamento do consumidor. São Paulo: Cengage Learning.

Camarena, D., Sanjuán, A., \& Philippidis, G. (2011). Influence of ethnocentrism and neo-phobia on ethnic food consumption in Spain. Appetite, 57, 121-130.

Chen, M-F. (2007). Consumer attitudes and purchase intentions in relation to organic foods in Taiwan: Moderating effects of food-related personality traits. Food Quality and Preference, 18, 1008-1021.

Cooke, L., \& Wardle, J. (2005). Age and gender differences in children's food preferences. British Journal of Nutrition, 93 (5), 741-746.

Costell, E., Tárrega, A., \& Bayarri, S. (2010). Food Acceptance: The Role of Consumer Perception and Attitudes. Chemosensory Perception, 3 (1), 42-50.

D'Antuono, L. F., \& Bignami, C. (2012). Perception of typical Ukrainian foods among an Italian population. Food Quality and Preference, 25, 1-8.

El-Kareh, A. C. (2008). Comida quente, mulher ausente: produção doméstica e comercialização de alimentos preparados no Rio de Janeiro no século XIX. Fazendo Gênero 8 - Corpo, Violência e Poder, Florianópolis, SC, Brasil.

Espinoza, F. da S., \& Nique, W. M. (2003). Experiências emocionais em situações de consumo de produtos: evidências e proposições de pesquisa. ENANPAD, Atibaia, SP, Brasil, 27.

EUFIC - European Food Information Council. (2014). EU project Connect4Action: Connecting key players in the food innovation process to improve consumer acceptance of new products. Recuperado de $\quad<\quad$ www.eufic.org/article/en/health-and-lifestyle/foodchoice/artid/Connecting_key_players_in_the_food_innovation_process_to_improve_consumer_ acceptance_of_new_products/>.

Federação das Indústrias do Estado de São Paulo - FIESP. (2010). Brasil Food Triends 2020. São Paulo.

Fernández-Ruiz, V., Claret, A., \& Chaya, C. (2013). Testing a Spanish-version of the Food Neophobia Scale. Food Quality and Preference, 28, 222-225.

Fischler, C. (1990). L'(H)omnivore. Barcelona: Anagrama.

Fishbein, M., \& Ajzen, I. (1975). Belief, Attitude, Intention, and Behavior: An Introduction to Theory and Research. Reading, MA: Addison-Wesley.

Frank, R. A., \& Klaauw, N. V. D. (1994). The contribution of chemosensory factors to individual differences in reported food preferences. Appetite, 22, 101-123. 
Garcia, R. W. D. (1994). Representações Sociais da Comida no Meio Urbano: algumas considerações para o estudo dos aspectos simbólicos da alimentação. Revista Cadernos de Debate, 2, 12-40.

Garcia, R. W. D. (2003). Reflexos da Globalização na cultura alimentar: considerações sobre as mudanças na alimentação urbana. Rev.Nut., Campinas, 16 (4), 483-492.

Hursti, U. K., Sjödén, P. (1997). Food and general neophobia and their relationship with selfreported food choice: Familial resemblance in Swedish families with children of ages 7-17 years. Appetite, 29, 89-103.

Instituto Brasileiro de Geografia e Estatística - IBGE. (2013). Pesquisa de Inovação: PINTEC 2011. Rio de Janeiro.

Jiang, Y., King, J. M., \& Prinyawiwatkul, W. (2014). A review of measurement and relationships between food, eating behavior and emotion. Trends in Food Science \& Technology, 36, 15-28.

Jodelet, D. (2001). As representações sociais. Rio de Janeiro: EdUERJ.

Koivisto, U., \& Sjödén, P. (1996). Food and general neophobia in Swedish families: Parent-child comparisons and relationships with serving specific foods. Appetite, 26, 107-118.

Macaux, A. L. B. (2001). Eat to live or live to eat? Do parents and children agree? Public Health Nutrition, 4, 141-146.

Meiselman, H., King, S., Gillette, M. (2010). The demographics of neophobia in a large commercial US sample. Food Quality and Preference, 21, 893-897.

Mooney, K. M., \& Walbourn, L. (2001). When college students reject food: not just a matter of taste. Appetite, 36, 41-50.

Nordin, S., Broman, D. A., Garvill, J., \& Nyroos, M. (2004) .Gender differences in factors affecting rejection of food in healthy young Swedish adults. Appetite, 43, 295-301.

Pliner, P., \& Hobden, K. (1992). Development of a scale to measure the trait of food neophobia in humans. Appetite, 19, 105-120.

Poulain, J.-P. (2004). Sociologias da alimentação. Florianópolis: UFSC.

Ritchey, P.N., Frank, R. A., Hursti, U-K., \& Tuorila, H. (2003). Validation and cross-national comparison of the food neophobia scale (FNS) using confirmatory factor analysis. Appetite, 40 (2), 163-173.

Robinson, C. H., \& Thomas, S. P. (2004). The interaction model of client health behavior as a conceptual guide in the explanation of children's health behaviors. Public Health Nutrition, 21 (1), 73-84.

Sanjuán-López, A., Philippidis, G., \& Resano-Ezcaray, H. (2011). How useful is acceptability to explain economic value? An application on the introduction of innovative saffron products into commercial markets. Food Quality and Preference, 22, 255-263.

Schickenberg, B., Assema, P. V., Brug, J., \& Vries, N. de. (2006). Level of food neophobia in Dutch adults and association with familiarity with and willingness to try new healthful food products. Appetite, 47, 257-279.

Sheth, J. N., Mittal, B., \& Newman, B. I. (2001). Comportamento do cliente: indo além do comportamento do consumidor. São Paulo: Atlas. 
Simonson, I., Carmon, Z., Dhar, R., Drolet, A., \& Nowlis, S. M. (2001). Consumer research: in search of identity. Annual Review of Psychology, 52, 249-275.

Thiel, D., \& Demontrond, R. (1997). Towards connectionist models of food consumer attitudes. Food Quality and Preference, 8 (5/6), 429-438.

Tuorila, H., Lähteenmäki, L., Pohjalainen, L., \& Lotti, L. (2001). Food neophobia among the Finns and related responses to familiar and unfamiliar foods. Food Quality and Preference, 12, 29-37.

Ventura, R. (2010). Mudanças no Perfil do Consumo no Brasil: Principais Tendências nos Próximos 20 Anos. [S.I.]: Macroplan - prospectiva, estratégia e gestão.

Vergara, S. C. (2005). Projetos e Relatórios de Pesquisa em Administração. São Paulo: Atlas.

Vieira, V. A., \& Tibola, F. (2005). Pesquisa qualitativa em marketing e suas variações: trilhas para pesquisas futuras. RAC, $9(2), 09-33$.

Visalberghi, E., \& Fragaszy, D. (1995). The behaviour of capuchin monkeys, Cebus apella, with novel food: the role of social context. Animal Behaviour, 49, 1089-1095.

Yamamoto, M. E., \& Lopes, F. A. (2004). Dize-me o que falas e te direi o que comes: aquisição da linguagem e composição da dieta em crianças. In MOURA, M. L. S. (Org.). O bebê do século XXI e a psicologia em desenvolvimento. São Paulo: Casa do Psicólogo.

Yamamoto, M. E., \& Lopes, F. A. (2006). A evolução do comportamento alimentar: selecionando o que comer. FAPERN, 1 (4), 21-24. 